\title{
Agreement between Self-Reports and Medical Records in the Reporting of Pregnancy Outcomes in Women with Type 1 Diabetes
}

\begin{abstract}
Andrea Rodgers Fischl ${ }^{1 \dagger}$, Denise Charron-Prochownik ${ }^{1 \dagger}$, Dorothy Becker ${ }^{2}$, William H. Herman ${ }^{3}$, Laura McEwen ${ }^{3}$, Corinne M. Plesko ${ }^{1}$, Frances Peterson-Burch ${ }^{1}$ and Susan M. Sereika ${ }^{*}$
\end{abstract}

${ }^{*}$ Correspondence: ssereika@pitt.edu

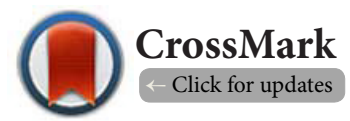

¥These authors contributed equally to this work.

'Department of Health Promotion and Development, University of Pittsburgh, School of Nursing, USA.

2Department of Pediatrics, Children's Hospital of Pittsburgh of UPMC, University of Pittsburgh, School of Medicine, USA.

${ }^{3}$ Department of Medicine, University of Michigan, USA.

${ }^{4}$ Department of Health and Community Systems and Center for Research and Evaluation, University of Pittsburgh,

School of Nursing, USA.

\begin{abstract}
Background: Since previous studies have shown that self-reports may not be as accurate as medical record data, this secondary analysis investigated the agreement between maternal self-report (SR) and medical record (MR) documentation of pregnancy outcomes (e.g., length of hospitalization, neonatal birth weight, complications) in women with type 1 diabetes (T1D).

Methods: An online SR follow-up study to evaluate long-term reproductive-health outcomes was conducted with women who previously participated in randomized controlled trials (RCT) to test a preconception counseling (PC) intervention (READY-Girls) as adolescents and included a matched comparison group of women with T1D who did not receive the PC intervention as teens. Data were collected from SR surveys and MR review. Agreement between SR and MR entries was assessed using kappa coefficients and intra-class correlation coefficients (ICC).

Results: Of the 101 women with T1D (51 RCT, 50 matched controls) who were recruited for long-term follow-up (98.0\% Caucasian, age range $18-34$ years, $82.0 \%$ had some college, T1D duration range 0-30 years), $18(17.8 \%)$ reported ever being pregnant and for $8(47.1 \%)$ of these women access to MR was obtained for 14 pregnancies. These women had a mean $\pm \mathrm{SD}$ age of $28.57 \pm 1.91$ years at entry and duration of T1D of 19.75 \pm 5.45 years. Perfect agreement (kappa $=1.0)$ was observed between SR and MR for type of delivery and neonatal birth weight $>9$ pounds. Excellent agreement was observed for neonatal weight (ICC=.951). Lower levels of agreement were found between SR and MR for duration of post-delivery hospitalization [maternal (ICC=.269); neonatal (ICC=.657)] and maternal and neonatal complications (kappa=.639 and kappa=.025, respectively).

Conclusion: There was excellent agreement for several pregnancy outcomes in these women with T1D. Self-report of pregnancy outcomes should be verified by medical record data, especially time-related variables which could be more difficult to recall, suggesting that method of reporting for these types of variables may not be interchangeable.
\end{abstract}

Keywords: Type 1 diabetes, medical records, self-report, pregnancy outcomes

\section{Introduction}

Women with diabetes have increased risks associated with pregnancy $[\mathbf{1 , 2}]$. Accurate data regarding pregnancy outcomes is imperative in this population. Therefore, selection of an ac- 
Fischl et al. Research Journal of Women's Health 2017,

curate data collection method for these outcomes became a primary concern of our study, and an aim of evaluation.

Our program of research is based on the following premise. To reduce the risks of complications with reproductive health in women with diabetes, the American Diabetes Association (ADA) recommends preconception counseling (PC) to start at puberty as part of standard care and it includes the following: 1) counseling about diabetes and pregnancy, specifically the malformation risk associated with unplanned pregnancies and poor metabolic control, and 2) effective use of contraception until metabolic control is attained/maintained (A1c < $7 \%$ ) and conception occurs $[3,4]$. Preconception counseling and care has reduced the risk of congenital malformations $[5,6]$ and has been associated with improved perinatal and maternal outcomes $[6,7]$.

Our program of research, called READY-Girls (Reproductivehealth Education and Awareness of Diabetes in Youth for Girls), was tailored for teens with type 1 diabetes (T1D), and later (2005) modified for type 2 diabetes (T2D), to promote effective family planning decisions and empower them to seek preconception care when planning a pregnancy. READY-Girls is a validated developmentally appropriate evidence-based educational PC intervention for adolescent girls starting at puberty [8-10]. Three randomized controlled trials (RCT) at multiple diabetes clinic sites using the READY-Girls intervention have been conducted (1999, 2002, and 2005) on teens 13-20 years of age and results have been previously reported [11-13]. Along-term follow-up survey study was later conducted online with past READY-Girls participants regarding $P C$ and pregnancy outcomes. The primary aim of this study was to examine the long-term outcomes of pregnancy planning behaviors, pregnancy outcomes and metabolic control in women with diabetes who received PC during adolescence (single or intensive READY-Girls interventions) compared to a matched comparison group who did not receive $R E A D Y$ Girls. An exploratory aim was to determine the long-term cost-benefit of READY-Girls. Because previous studies have shown that data from self-reports (surveys) may not be completely accurate [14-20], medical record data were also obtained. Participants who reported a pregnancy were asked to provide information on the above variables in the selfreported survey; in addition, these data were extracted from the medical records. The purpose of this secondary analysis was to investigate the agreement between self-reported (SR) data and medical record (MR) data for maternal and neonatal outcomes in women with T1D.

\section{Materials and methods}

This study was a secondary analysis conducted to evaluate the agreement between SR and MR data that included the following variables of interest: type of delivery, pregnancy outcome, maternal and neonatal length of post-delivery hospital stay, neonatal weight (actual weight in pounds and weight $>9$ pounds), and having any maternal and neonatal complications.

The parent study was a long-term follow-up study employing a prospective, repeated measures design which included previous participants at one site in southwestern Pennsylvania from a possible pool of 115 participants across the three READY-Girls RCTs who were at least 18 years of age and had T1D. This site is a large pediatric tertiary care research intensive institute which maintains a pre-established registry for pediatric patients with T1D born since 1955. Other participants recruited from this registry served as the comparison group. These women with T1D were matched to the READY-Girls RCT participants according to age (within 2 years), race (white, nonwhite), and duration of T1D (within 2 years). After Institutional Review Board (IRB) approval, both the previous READY-Girl participants and the potential comparison women were recruited through phone calls, mailed letters and face-to-face contact by the project nurse in the diabetes clinic. Previous consent forms from the RCTs contained statements allowing former participants to be re-contacted. The project nurse explained the study in detail, consented the participants and provided web access instructions for the follow-up surveys.

Participants who identified a pregnancy in the baseline or subsequent follow-up surveys (at 6, 12 and 18 months) were contacted by letter stating the importance and rationale to a follow-up medical record review of their pregnancy. At that time, participants were asked to sign and return consent for the ascertainment of their medical records and those of their baby. However, not all participants allowed access to their medical records. Upon receipt of the consent, a research associate sent a copy of the consent and a letter to the identified hospital for the medical records for the reported pregnancy. After review of the medical record, the first research associate entered the data onto a TELEform and the second research associate visually verified the data entry after an independent review of the medical record.

Pregnancy outcomes (maternal and neonatal outcomes) were measured by self-report and medical records for each pregnancy documented. Interval or ratio level outcomes included maternal and neonatal length of hospital stay and neonatal weight (actual weight in pounds). Nominal scaled outcomes included any maternal and fetal complications, type of delivery, pregnancy outcome (i.e., live birth, stillborn, miscarriage/elective abortion), and neonatal weight $>9$ pounds. Demographic and clinical data were also obtained (age, race, education, income, health insurance, living arrangements, marital status, religion, age at T1D diagnosis, duration of T1D) for sample description.

Based on a variable's level of measurement and observed data distribution, appropriate summary statistics were used to describe the total sample and subsamples based on pregnancy status and whether medical records could be obtained. Group comparative statistics (two-sample t-test or Mann-Whitney U-test for continuous type variables and contingency table analysis with chi-square test of independence with exact 
estimation of $p$-values for categorical variables) were used to compare the subsamples based on self-reported pregnancy status and whether maternal medical records were able to be obtained for women who were ever pregnant. Agreement between mother's self-report and the report in the medical record for selected pregnancy outcomes and maternal and neonatal complications was assessed using either unweighted or weighted kappa coefficients for categorical outcomes and intra-class correlation coefficients (ICC) for continuous type outcomes. Empirical work suggest poor agreement for kappa coefficients less than .40, fair to good agreement for kappa coefficients ranging from .40 to .75 , and excellent agreement for kappa coefficients greater than .75, with kappa coefficients equal to 1 indicating perfect agreement.

\section{Results}

Of the 101 participants with T1D in the follow-up study, 18 (17.8\%) self-reported ever being pregnant, with a total of 35 pregnancies being reported at the baseline assessment or during the 18-month follow-up period of the parent study. Women who reported ever being pregnant were demographically and clinically similar to women who reported never being pregnant ( $p \geq .05)$, except with regards to marital status, living arrangements, age at entry into the follow-up study, and duration of T1D $(p<.05)$. As anticipated, women who reported ever being pregnant were more likely to be married $(p<.001)$, currently having a husband or boyfriend $(p=.011)$, living with their husband $(p<.001)$ and/or biological children $(p<.001)$, and were older $(p<.001)$ and had T1D longer $(p<.001)$ than women who reported never being pregnant.

As reported in Table 1, the women $(n=8)$ providing both SR and MR data were similar to those women providing only SR data $(n=10)$, except for marital status where women providing both sources of data were more likely to be married $(p=.036)$. Examining the self-reported information regarding the 35 pregnancies, most $(n=24,77.4 \%)$ were self-reported as deliveries greater than 20 weeks. The distribution of possible pregnancy outcomes was similar between those women providing MR data and those who did not $(p=.481)$.

Focusing on women with both data sources, we examined the agreement in the reporting of selected pregnancy outcomes (see Table 2). Of the 14 pregnancies for which MR data were obtained, most were $(n=13,92.9 \%)$ deliveries greater than 20 weeks. The remaining pregnancy was self-reported

Table 1. Comparisons between participants who have ever been pregnant with and without medical record (MR) data on selected characteristics provided through self-report (SR) (n=18).

\begin{tabular}{|c|c|c|c|c|}
\hline Characteristic & $\begin{array}{l}\text { Total } \\
(\mathbf{n}=18) \\
\text { Mean } \pm \text { SD } \\
\text { or } \mathbf{n}(\%) \\
\end{array}$ & $\begin{array}{l}\text { SR only } \\
(\mathbf{n}=10) \\
\text { Mean } \pm \text { SD } \\
\text { or } \mathbf{n}(\%)\end{array}$ & $\begin{array}{l}\text { SR and MR }(n=8) \\
\text { Mean } \pm \text { SD } \\
\text { or } n(\%)\end{array}$ & $\begin{array}{l}\text { Test Statistic } \\
\text { p-value }\end{array}$ \\
\hline Race (Caucasian) & $18(100)$ & $10(100)$ & $8(100)$ & $\begin{array}{l}-- \\
--\end{array}$ \\
\hline Age at First Pregnancy (years) $(n=17)$ & $25.00 \pm 3.89$ & $25.00 \pm 3.81$ & $25.00 \pm 4.24$ & $\begin{array}{l}\mathrm{t}=0.000 \\
\mathrm{p}=1.000\end{array}$ \\
\hline Age at Entry (years) & $28.39 \pm 4.07$ & $28.10 \pm 5.32$ & $28.57 \pm 1.91$ & $\begin{array}{l}\mathrm{t}=-0.358 \\
\mathrm{p}=.726\end{array}$ \\
\hline Age at T1D Diagnosis (years) & $8.72 \pm 4.90$ & $8.60 \pm 4.95$ & $8.87 \pm 5.17$ & $\begin{array}{l}\mathrm{t}=-0.115 \\
\mathrm{p}=.910\end{array}$ \\
\hline Duration of T1D (years) & $19.67 \pm 6.17$ & $19.60 \pm 7.00$ & $19.75 \pm 5.45$ & $\begin{array}{l}\mathrm{t}=-0.050 \\
\mathrm{p}=.961\end{array}$ \\
\hline $\begin{array}{l}\text { Marital Status } \\
\text { Never Married } \\
\text { Married } \\
\text { Divorced/Separated/Widowed } \\
\end{array}$ & $\begin{array}{l}5(27.8) \\
12(66.7) \\
1(5.6)\end{array}$ & $\begin{array}{l}5(50.0) \\
5(50.0) \\
0(0)\end{array}$ & $\begin{array}{l}0(0) \\
7(87.5) \\
1(12.5)\end{array}$ & $\begin{array}{l}\mathrm{X}^{2}=6.188 \\
\mathrm{p}=.036\end{array}$ \\
\hline $\begin{array}{l}\text { Highest Level of Education } \\
\text { High School } \\
\text { Some College/Trade School } \\
\text { College } \\
\text { Graduate school } \\
\end{array}$ & $\begin{array}{l}3(16.7) \\
6(33.3) \\
3(16.7) \\
6(33.3)\end{array}$ & $\begin{array}{l}1(10.0) \\
4(40.0) \\
1(10.0) \\
4(40.0)\end{array}$ & $\begin{array}{l}2(25.0) \\
2(25.0) \\
2(25.0) \\
2(25.0)\end{array}$ & $\begin{array}{l}\mathrm{X}^{2}=1.800 \\
\mathrm{p}=.671\end{array}$ \\
\hline $\begin{array}{l}\text { Income }(\mathrm{n}=17) \\
\quad<\$ 40,000 \\
\quad \$ 40,000-<\$ 70,000 \\
\geq \$ 70,000\end{array}$ & $\begin{array}{l}6(35.3) \\
3(17.6) \\
8(47.1)\end{array}$ & $\begin{array}{l}5(55.6) \\
0(0) \\
4(44.4)\end{array}$ & $\begin{array}{l}1(12.5) \\
3(37.5) \\
4(50.0)\end{array}$ & $\begin{array}{l}\mathrm{X}^{2}=5.627 \\
\mathrm{p}=.071\end{array}$ \\
\hline $\begin{array}{l}\text { Health Insurance }(\mathrm{n}=16) \\
\text { Private } \\
\text { Medicaid/Medical Assistance/Medicare }\end{array}$ & $\begin{array}{l}12(75.0) \\
4(25.0)\end{array}$ & $\begin{array}{l}7(70.0) \\
3(30.0)\end{array}$ & $\begin{array}{l}5(83.3) \\
1(16.7)\end{array}$ & $\begin{array}{l}\mathrm{X}^{2}=0.356 \\
\mathrm{p}=0.511\end{array}$ \\
\hline
\end{tabular}

$\mathrm{T} 1 \mathrm{D}=$ Type 1 diabetes 
Fischl et al. Research Journal of Women's Health 2017,

http://www.hoajonline.com/journals/pdf/2054-9865-4-6.pdf

Table 2. Agreement between Self-Report and Medical Record Data for Selected Pregnancy Outcomes ( $n=14$ pregnancies).

\begin{tabular}{|c|c|c|c|}
\hline Pregnancy Outcome & $\begin{array}{l}\text { Self-Report } \\
\text { Mean } \pm \text { SD } \\
\text { or } \mathbf{n}(\%)\end{array}$ & $\begin{array}{l}\text { Medical Record } \\
\text { Mean } \pm \text { SD } \\
\text { or } n(\%)\end{array}$ & $\begin{array}{l}\text { Measure of } \\
\text { Agreement }\end{array}$ \\
\hline $\begin{array}{l}\text { Pregnancy Outcome } \\
\text { Delivery (> } 20 \text { weeks) } \\
\text { Stillborn } \\
\text { Miscarriage/Elective Abortion }\end{array}$ & $\begin{array}{l}13(92.9) \\
0(0) \\
1(7.1)\end{array}$ & $\begin{array}{l}13(92.9) \\
1(7.1) \\
0(0)\end{array}$ & kappa $=.482$ \\
\hline $\begin{array}{l}\text { Type of Delivery }(\mathrm{n}=13) \\
\text { Vaginal } \\
\text { Cesarean } \\
\end{array}$ & $\begin{array}{l}6(46.2) \\
7(53.8) \\
\end{array}$ & $\begin{array}{l}6(46.2) \\
7(53.8)\end{array}$ & kappa $=1.000$ \\
\hline $\begin{array}{l}\text { Neonatal Weight at Birth }>9 \text { pounds }(n=13) \\
\text { No } \\
\text { Yes }\end{array}$ & $\begin{array}{l}9(69.2) \\
4(30.8)\end{array}$ & $\begin{array}{l}9(69.2) \\
4(30.8)\end{array}$ & kappa $=1.000$ \\
\hline $\begin{array}{l}\text { Neonatal Weight at Delivery (pounds) } \\
(n=13)\end{array}$ & $7.67 \pm 1.70$ & $7.91 \pm 1.47$ & $\mathrm{ICC}=.951$ \\
\hline $\begin{array}{l}\text { Maternal Length of Stay Following Delivery } \\
\text { (days) }(n=13)\end{array}$ & $2.92 \pm 1.44$ & $2.00 \pm 1.08$ & $\mathrm{ICC}=.296$ \\
\hline Neonatal Length of Stay (days) $(n=13)$ & $3.62 \pm 2.02$ & $3.08 \pm 1.66$ & $\mathrm{ICC}=.657$ \\
\hline $\begin{array}{l}\text { Maternal Complications }(\mathrm{n}=13) \\
\text { No } \\
\text { Yes }\end{array}$ & $\begin{array}{l}4(30.8) \\
9(69.2)\end{array}$ & $\begin{array}{l}4(30.8) \\
9(69.2)\end{array}$ & kappa $=.639$ \\
\hline $\begin{array}{l}\text { Neonatal Complications }(\mathrm{n}=13) \\
\text { No } \\
\text { Yes }\end{array}$ & $\begin{array}{l}5(38.5) \\
8(61.5)\end{array}$ & $\begin{array}{l}5(38.5) \\
8(61.5)\end{array}$ & kappa $=.025$ \\
\hline
\end{tabular}

ICC $=$ intra-class coefficient correlation

as an elective abortion greater than 20 weeks; however, the pregnancy was listed as a stillbirth with a major brain/spinal anomaly in the medical record (kappa=.482). Perfect agreement (kappa $=1.000$ ) between SR and the MR report was observed for the type of delivery and whether the baby's weight was greater than 9 pounds. Although mothers on average tended to underreport their baby's weight relative to that reported in the medical record, the agreement in reporting the neonatal actual weight was excellent $(I C C=.951)$. In contrast, mothers on average reported longer lengths of hospital stay following delivery for both their baby as well as themselves compared to the medical record, with good agreement for the baby's length of stay (ICC $=.657)$ but poor agreement for their own post-delivery hospital stay (ICC=.296). Regarding maternal complications, the same frequency distributions were observed for both SR and MR with good agreement between mother's SR and MR (kappa=.639). Although the same frequency distributions were observed for neonatal complications for SR and MR, very poor agreement was observed (kappa=.025).

\section{Discussion}

Accuracy of reporting outcomes surrounding pre-pregnancy, pregnancy and delivery is necessary in determining the cost-effectiveness and efficacy of preconception counseling programs in women with diabetes. While maternal reporting of perinatal events is assumed to be accurate, review of medical records is the gold standard for assuring the reliability for cost data. However, medical record reviews can be costly and time-consuming. As an exploratory aim of this study, medical record reviews of maternal and neonatal outcomes of pregnancies among former READY-Girls participants and a comparison group was conducted to determine the longterm cost-benefit of READY-Girls. Since not all participants allowed access to their medical records, the purpose of this secondary analysis was to investigate agreement between self-report and medical records for maternal and neonatal outcomes in women with T1D.

Several of the pregnancy outcomes had high agreement. Similar to what we observed for neonatal weight-related outcomes as previously reported in the literature, maternal recall of neonatal birth weight was highly accurate [21]. The high to perfect level of agreement between the SR and MR data for several of the pregnancy outcomes in these participants with T1D is similar to previous studies showing excellent agreement for mode of delivery $[22,23]$. These findings suggest that self-report of some pregnancy outcomes, such as type of delivery and neonatal weight, can be accurate.

Pregnancy outcomes having good agreement were neonatal length of hospital stay and maternal complications. Mothers may be accurate in recalling neonatal length of hospital stay as this occurs solely post-delivery [24].

Lastly, poor agreement was noted for maternal length of hospital stay post-delivery and neonatal complications. For durations of stay in the hospital mother's perceptions of time 
may be distorted due to recall and may not be consistent with a hospital's recording of length stay [19]. For mothers the total length of hospital stay may include periods of predelivery, delivery and post-delivery [22], and mothers may not be able to specifically recall time during the post-delivery period. Regarding neonatal complications, our finding of poor agreement were consistent with previous results [22]. In our study, mother's self-report on neonatal complications was more general, and agreement might have been better had we targeted specific complications (e.g., jaundice, hypoglycemia).

This study had several limitations that should be acknowledged, including the small sample size, limited variability as to the type of pregnancy outcome (i.e., most were deliveries), and only a limited detail as to the type of maternal and neonatal complication based on mother's self-report.

\section{Conclusions}

Self-report of pregnancy outcomes should be verified by medical record data whenever possible, especially time-related variables which could be more difficult to recall. There was excellent agreement between the self-report and medical record data for several of the pregnancy outcomes in these participants with T1D. Overreliance on self-report data alone may lead to inaccurate results for history intakes for clinical practice and research such as cost analyses. When possible medical record data should be collected to validate selfreport data. Further analysis of specific maternal/neonatal complications is needed to determine differences between the two report types.

\section{Competing interests}

The authors declare that they have no competing interests.

\section{Acknowledgements}

Funded by American Diabetes Association Award: (20112013) 1-11-CT-10. The study team would like to thank Blair Powell, Ana Diaz, Jennifer Thurheimer, Jessica Choi, Kaitlin Malone, and our participants for their assistance and support for this project. Data were presented at the American Diabetes Association 73rd Scientific Sessions in Chicago IL in June 2013.

\section{Publication history}

Editor: Erich Cosmi, University of Padua, Italy.

Received: 22-Nov-2017 Final Revised: 11-Dec-2017

Accepted: 12-Dec-2017 Published: 23-Dec-2017

Authors' contributions

\begin{tabular}{|l|c|c|c|c|c|c|c|c|}
\hline Authors' Contributions & ARF & SMS & WHH & LMCE & DB & CMP & DCP & FPB \\
\hline Research Concept and Design & $\checkmark$ & $\checkmark$ & -- & -- & -- & -- & $\checkmark$ & -- \\
\hline Collection and/or assembly of data & $\checkmark$ & -- & -- & -- & -- & $\checkmark$ & -- & -- \\
\hline Data analysis and interpretation & $\checkmark$ & $\checkmark$ & $\checkmark$ & $\checkmark$ & $\checkmark$ & -- & $\checkmark$ & -- \\
\hline Writing the article & $\checkmark$ & $\checkmark$ & -- & -- & -- & $\checkmark$ & $\checkmark$ & $\checkmark$ \\
\hline Critical revision of the article & $\checkmark$ & $\checkmark$ & $\checkmark$ & $\checkmark$ & $\checkmark$ & $\checkmark$ & $\checkmark$ & $\checkmark$ \\
\hline Final approval of article & $\checkmark$ & $\checkmark$ & $\checkmark$ & $\checkmark$ & $\checkmark$ & $\checkmark$ & $\checkmark$ & $\checkmark$ \\
\hline Statistical Analysis & $\checkmark$ & $\checkmark$ & -- & -- & -- & -- & $\checkmark$ & - \\
\hline
\end{tabular}

\section{References}

1. Kitzmiller J, Cloherty J, Younger M, Tabatabaii A, Rothchild S, Sosenko J, Epstein MF Singh SH, and Neff RK. Diabetic pregnancy and perinatal mortality. J Obstet Gynecol. 1978, 131:560-80.

2. Jovanovic $L$ and Peterson $C M$. Management of the pregnant, insulindependent diabetic woman. Diabetes Care. 1980; 3:63-8. I PubMed

3. Standards of medical care in diabetes--2009. Diabetes Care. 2009; 32 Suppl 1:S13-61. | Article | PubMed Abstract | PubMed FullText

4. American Diabetes Association. Standards of Medical Care in Diabetes2017. Diabetes Care. 2017; 40:1-142. | Article

5. Herman WH and Charron-Prochownik D. Preconception counseling: an opportunity not to be missed. Clin Diabetes 2000, 18:122-3.

6. Kitzmiller JL, Gavin LA, Gin GD, Jovanovic-Peterson L, Main EK and Zigrang WD. Preconception care of diabetes. Glycemic control prevents congenital anomalies. JAMA. 1991; 265:731-6. | Article I PubMed

7. Rosenn B, Miodovnik M, Combs CA, Khoury J and Siddiqi TA. Preconception management of insulin-dependent diabetes: improvement of pregnancy outcome. Obstet Gynecol. 1991; 77:846-9. I PubMed

8. Charron-Prochownik D, Hannan MF, Sereika SM, Becker D, and RodgersFischl A. How to develop CD-ROMs for diabetes education: Exemplar "Reproductive-health Education and Awareness of Diabetes in Youth for Girls" (READY-Girls). Diabetes Spectr. 2006; 19:110-5. I Article

9. Downs J and Charron-Prochownik D. READY-Girls (DVD). 2008.
10. Charron-Prochownik D and Downs J. READY-Girls-- Reproductive-health Education \& Awareness of Diabetes in Youth for Girls. 2009; 1-39.

11. Fischl AF, Herman WH, Sereika SM, Hannan M, Becker D, Mansfield MJ, Freytag LL, Milaszewski K, Botscheller AN and Charron-Prochownik D. Impact of a preconception counseling program for teens with type 1 diabetes (READY-Girls) on patient-provider interaction, resource utilization, and cost. Diabetes Care. 2010; 33:701-5. I Article I PubMed Abstract | PubMed FullText

12. Charron-Prochownik D, Ferons-Hannan M, Sereika S and Becker D. Randomized efficacy trial of early preconception counseling for diabetic teens (READY-girls). Diabetes Care. 2008; 31:1327-30. I Article I PubMed Abstract | PubMed FullText

13. Charron-Prochownik D, Sereika SM, Becker D, White NH, Schmitt P, Powell AB, 3rd, Diaz AM, Jones J, Herman WH, Fischl AF, McEwen L, DiNardo M, Guo F and Downs J. Long-term effects of the boosterenhanced READY-Girls preconception counseling program on intentions and behaviors for family planning in teens with diabetes. Diabetes Care. 2013; 36:3870-4. | Article | PubMed Abstract | PubMed FullText

14. Sanderson M, Williams MA, White E, Daling JR, Holt VL, Malone KE, Self SG and Moore DE. Validity and reliability of subject and mother reporting of perinatal factors. Am J Epidemiol. 1998; 147:136-40. | PubMed

15. Sou SC, Chen WJ, Hsieh WS, and Jeng SF. Severe obstetric complications 
Fischl et al. Research Journal of Women's Health 2017,

and birth characteristics in preterm or term delivery were accurately recalled by mothers. J Clin Epidemiol. 2006; 59:429-35. | Article

16. Van Gelder MMHJ, Van Rooij IALM, De Walle HEK, Roeleveld N, and Bakker MK. Maternal recall of prescription medication use during pregnancy using a paper-based questionnaire: A validation study in the Netherlands. Drug Saf. 2013; 36:43-54. | Article

17. Buka SL, Goldstein JM, Spartos E and Tsuang MT. The retrospective measurement of prenatal and perinatal events: accuracy of maternal recall. Schizophr Res. 2004; 71:417-26. | Article | PubMed

18. Yawn BP, Suman VJ and Jacobsen SJ. Maternal recall of distant pregnancy events. J Clin Epidemiol. 1998; 51:399-405. | Article | PubMed

19. Alves E, Lunet N, Correia S, Morais V, Azevedo A and Barros H. Medical record review to recover missing data in a Portuguese birth cohort: agreement with self-reported data collected by questionnaire and interrater variability. Gac Sanit. 2011; 25:211-9. | Article | PubMed

20. Harlow $S$ and Linet M. Agreement between questionnaire data and medical records: the evidence for accuracy of recall. Am J Epidemiol. 1989; 129:223-48.

21. Gofin R, Neumark YD and Adler B. Birthweight recall by mothers of Israeli children. Public Health. 2000; 114:161-3. | Article | PubMed

22. Troude P, L'Helias Laurence Foix, Raison-Boulley AM, Castel C, Pichon C, Bouyer J, and De La Rochebrochard E. Perinatal factors reported by mothers: Do they agree with medical records? Eur J Epidemiol. 2008; 23:557-64. | Article

23. Quigley MA, Hockley C and Davidson LL. Agreement between hospital records and maternal recall of mode of delivery: Evidence from 12391 deliveries in the UK Millennium Cohort Study. BJOG An Int J Obstet Gynaecol. 2007; 114:195-200. | Article

24. Bryant $\mathrm{HE}$, Visser $\mathrm{N}$ and Love EJ. Records, recall loss, and recall bias in pregnancy: a comparison of interview and medical records data of pregnant and postnatal women. Am J Public Health. 1989; 79:78-80. Article | PubMed Abstract | PubMed FullText

\section{Citation:}

Fischl AR, Charron-Prochownik D, Becker D, Herman WH, McEwen L, Plesko CM, Peterson-Burch F and Sereika SM. Agreement between Self-Reports and Medical Records in the Reporting of Pregnancy Outcomes in Women with Type 1 Diabetes. Res J Womens Health. 2017; 4:6.

http://dx.doi.org/10.7243/2054-9865-4-6 